\title{
Various Sulfatase Activities in Leukocytes and Cultured Skin Fibroblasts from Heterozygotes for the Multiple Sulfatase Deficiency (Mukosulfatidosis)
}

\author{
YOSHIKATSU ETO, ${ }^{(2)}$ TAKAHIRO TAHARA, TOSHIHARU TOKORO, AND KIHEI MAEKAWA
}

Department of Pediatrics, Tokyo Jikei University School of Medicine, Minato-ku, Tokyo, Japan

\begin{abstract}
Summary
In heterozygotes for multiple sulfatase deficiency (MSD), several sulfatase activities including arylsulfatases $\mathrm{A}, \mathrm{B1}, \mathrm{B} 2$, and $\mathrm{C}$, and cholesterol sulfatase were $40-50 \%$ of normals in cultured skin fibroblasts and 70-80\% of normals in leukocytes. In MSD patients, these enzyme activities were deficient or reduced. DEAE-Sepharose column chromatographic patterns of 4-methylumbelliferyl sulfatases A, B1, and B2 in leukocytes and cultured skin fibroblasts from MSD patients and heterozygotes were also consistent with the above data. These data indicate that several sulfatase activities in heterozygotes of MSD exhibited intermediate activities as observed in the heterozygote state of other autosomal recessive inherited diseases.
\end{abstract}

\section{Abbreviations}

MDS, multiple sulfatase deficiency

MLD, metachromatic leukodystrophy

4-MU, 4-methylumbelliferyl

Multiple sulfatase deficiency (MSD) is an autosomal recessive disorder, which is clinically characterized by gargoyl-like appearance, skeletal abnormality, hepatosplenomegaly, and ichthyosis $(1,2)$. Biochemically, the accumulation of sulfatide, acid mucopolysaccharides, and cholesterol sulfate accompanies deficiencies of arylsulfatases $\mathrm{A}, \mathrm{B}$, and $\mathrm{C}$, mucopolysaccharide sulfatases (sulfoiduronate sulfatase, sulfamidase, galactosamine-4-sulfatase, galactosamine-6-sulfatase) and steroid sulfatases (cholesterol sulfatase, dehydroepiandrosterone sulfatase, estrone sulfatase, pregnenolone sulfatase) in patients' tissues and cultured skin fibroblasts $(1,2,3,7,18)$.

This disorder is of considerable theoretical interest in genetics, because there are deficient activities of several different enzymes. In terms of the genetic controlling mechanisms of sulfatases, it is important to determine whether sulfatase activities in the heterozygote exhibit intermediate activities.

This report demonstrates that various sulfatase activities in heterozygotes were about one-half of controls in cultured skin fibroblasts and $70-80 \%$ of controls in leukocytes. In addition, the arylsulfatase characteristics in MSD patients were indistinguishable from those in normals.

\section{MATERIALS AND METHODS}

The clinical and biochemical findings of a Japanese case of MSD were reported previously (9).

Cell preparations. Leukocytes from MSD, metachromatic leukodystrophy (MLD), and their heterozygotes (father and mother) were prepared as described by Snyder and Brady (20). Fibroblasts were cultivated from skin biopsies from normal controls, MLD,
MSD, and a MSD obligate heterozygote (mother). Three different cell cultures of MSD proband were kindly obtained from Prof. $\mathrm{H}$. Kihara (University of California, Pomona USA). Two MSD probands (GM 3245 and GM 2407) and two MSD heterozygote cell cultures (GM 2644 and GM 2667) were shipped from the Human Genetic Cell Repository, Camden, NJ. The cultures were grown under conditions described previously (7). The leukocyte or fibroblast cells were suspended in $0.05 \mathrm{M}$ Tris- $\mathrm{HCl}$ buffer, $\mathrm{pH}$ 7.4 and dialyzed overnight against $0.02 \mathrm{M}$ Tris- $\mathrm{HCl}$ buffer $(\mathrm{pH}$ 7.4). The cells were disrupted by sonication for $60 \mathrm{sec}$ at 40 " $\mathrm{K}$ " cycles in a Branson sonifier. The homogenates were used for enzyme assays of arylsulfatase $\mathrm{C}$, cholesterol sulfatase, and heparin $\mathrm{N}$-sulfatase. For the determination of other sulfatases (arylsulfatases $\mathrm{A}$ and $\mathrm{B}$ ), the homogenate was centrifuged at $100,000 \times g$ for $30 \mathrm{~min}$ and the clear supernatant was used for enzyme assays. For the fractionation with DEAE-Sepharose column chromatography, the soluble fraction was used.

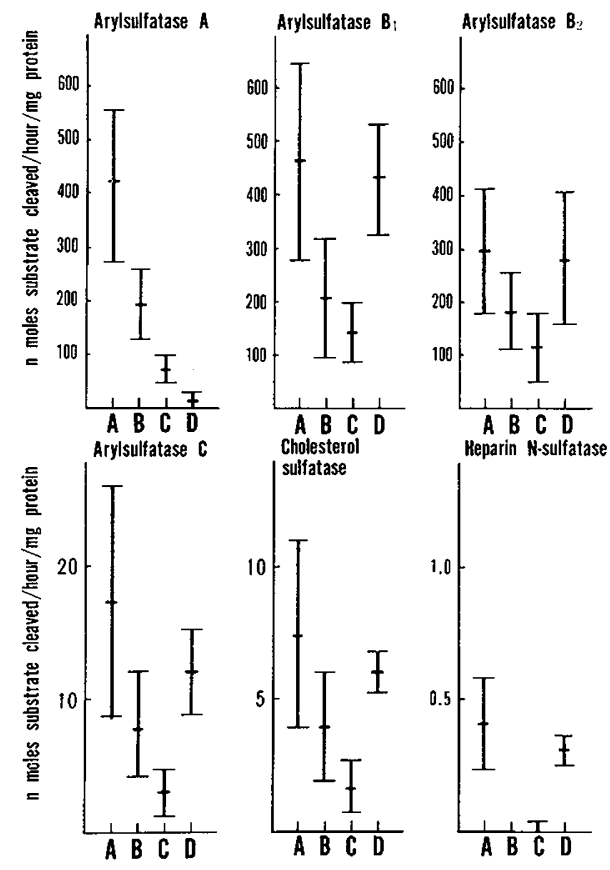

Fig. 1. Various sulfatase activities in cultured skin fibroblasts from patients with metachromatic leukodystrophy (MLD), multiple sulfase deficiency (MSD), and their heterozygotes. $(A)$, control subjects $(n=10)$; $(B)$ heterozygotes of $\operatorname{MSD}(n=3) ;(C)$ MSD patients $(n=5)$; and $(D)$ MLD $(n=3)$. The activities were expressed as nmoles substrate cleaved/ $\mathrm{h} / \mathrm{mg}$ protein, mean \pm standard deviation. " $n$ " indicates the number of different cell lines used. 

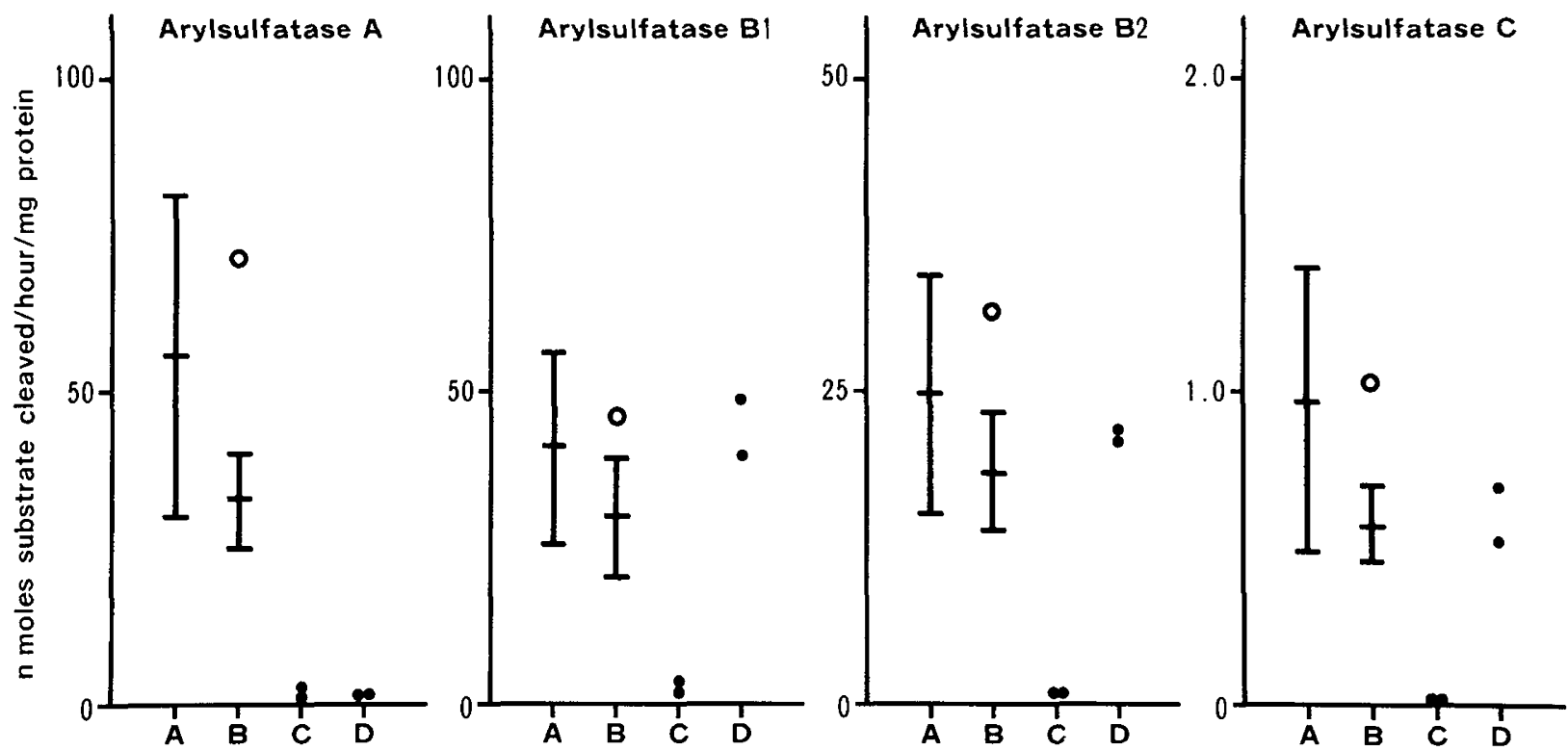

Fig. 2. Arylsulfatases A, B1, B2, and C activities in leukocyte from patients with metachromatic leukodystrophy (MLD), multiple sulfase deficiency (MSD), and their heterozygotes. $(A)$, control subjects $(n=8) ;(B)$ heterozygotes of MSD $(n=2)^{*}$, open circles indicate a sister of MSD patient; $(C)$, MSD patient; and $(D)$, MLD patients. * The data of mean and standard deviation were obtained from at least two different collections of leukocyte specimens. The activities were expressed as nmoles substrate cleaved $/ \mathrm{h} / \mathrm{mg}$ protein, mean \pm standard deviation. " $n$ " indicates the number of patients studied.

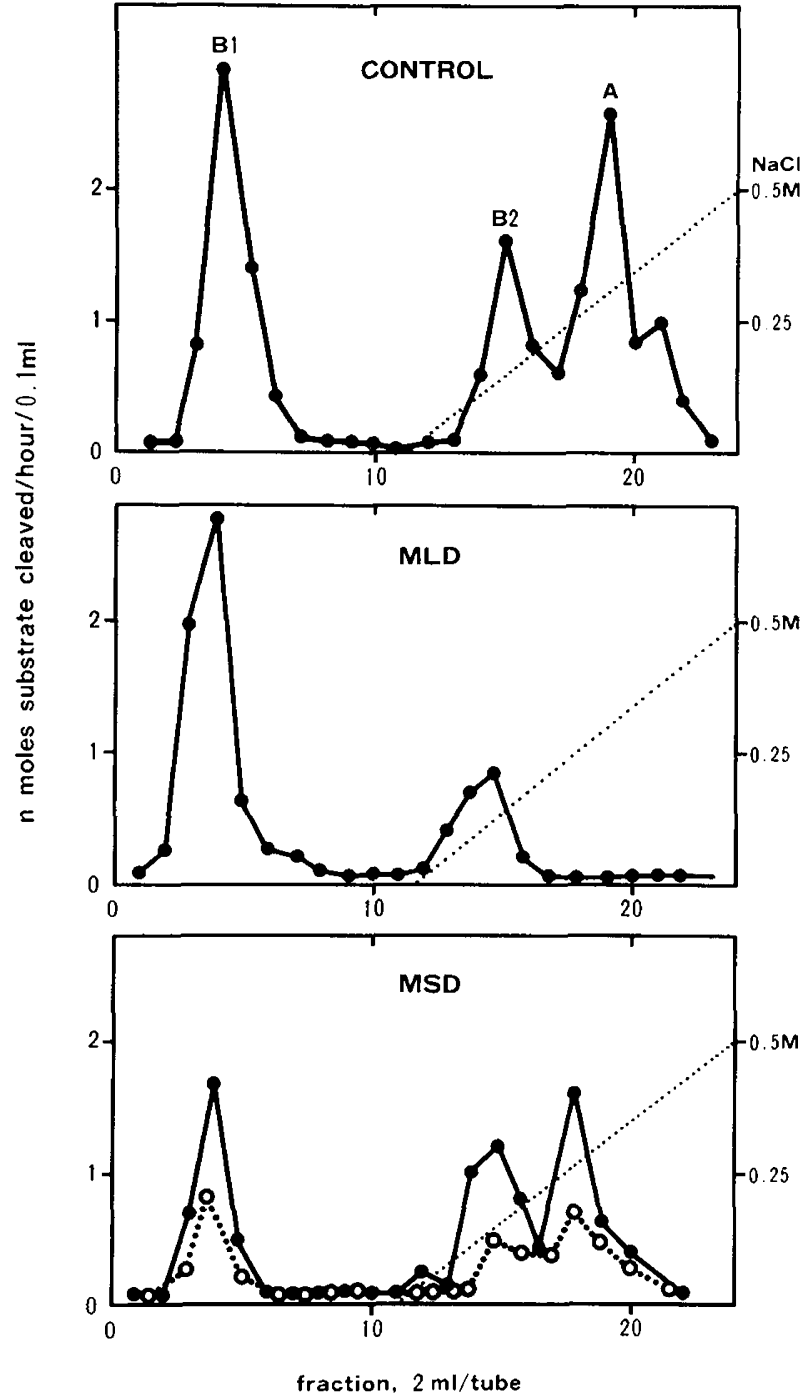

Fig. 3. DEAE-Sepharose column chromatographic patterns of 4-methylumbelliferyl (4-MU) sulfatase in cultured skin fibroblasts from control (top), metachromatic leukodystrophy MLD (middle) and multiple sulfase
Enzyme assay. Arylsulfatase A activity was determined using $p$ nitrocatechol sulfate as a substrate according to Baum et al. (4). Arylsulfatase $\mathrm{B} 1$ and $\mathrm{B} 2$ activities were determined using $p$-nitrocatechol sulfate by correction with DEAE-Sepharose column chromatographic patterns, because arylsulfatase B activity contained 30-40\% of arylsulfatase A activity, as shown in Figure 1. 4Methylumbelliferyl (4-MU) sulfatase was determined using 4-MU sulfate (Koch-Light) as follows: the incubation mixtures contained $100 \mu \mathrm{l}$ of $10 \mathrm{mM} 4-\mathrm{MU}$ sulfate dissolved in $0.2 \mathrm{M}$ sodium acetate buffer (pH 5.0) and $100 \mu \mathrm{l}$ of cell homogenates. The incubation was terminated by the addition of $0.2 \mathrm{M}$ glycine-carbonate buffer ( $\mathrm{pH} 10.8$ ) after $30-60 \mathrm{~min}$ incubation. Arylsulfatase $\mathrm{C}$ was measured using 4-MU sulfate as a substrate according to Eto et al. (7). Cholesterol sulfatase was determined using $\left[{ }^{14} \mathrm{C}\right]$-cholesterol sulfate (specific activity, 10-25 Ci/mmole) (a gift from Dr. Iwamori, Department of Biochemistry, University of Tokyo), as described previously (8). Heparin N-sulfatase was measured by the method of Schmidt et al. (19), using radioactive (N-sulfonate $\left[{ }^{35} \mathrm{~S}\right]$ ) heparin (Amersham, Chicago). Protein was estimated by the method of Lowry et al. (16).

$D E A E$-Sepharose column chromatography. The soluble fraction was subjected to DEAE-Sepharose column chromatography (11) for the fractionation of arylsulfatases from MLD, MSD, and their heterozygotes. The elution was performed by a continuous gradient of sodium chloride from $0-0.5 \mathrm{M} \mathrm{NaCl}$. Each fraction after column chromatography was dialyzed against $5 \mathrm{mM}$ sodium acetate buffer ( $\mathrm{pH}$ 6.0) and studied for $\mathrm{Km}$, thermostability, optimal $\mathrm{pH}$ and effects of ions.

\section{RESULTS}

Various sulfatase activities in cultured skin fibroblasts (Fig. 1). Various sulfatase activities including arylsulfatases A, Bl and B2, and $C$, cholesterol sulfatase, and heparin $\mathrm{N}$-sulfatase were shown in Figure 1. Arylsulfatase A activity was $16 \%$ less than that of controls in five different cells of MSD patients and 45\% less in three cell lines of MSD heterozygotes. Arylsulfatases B1 and B2 activities were $30 \%$ and $36 \%$ of controls in MSD patients and $45 \%$ and 52\% in MSD heterozygotes, respectively. Arylsulfatase C and cholesterol sulfatase were $20 \%$ less than that in patients and $43 \%$

deficiency (MSD) (bottom) (MSD patient, $\mathrm{O}-\mathrm{O}$; its heterozygote - ). The activities were normalized on the basis of $0.5 \mathrm{mg}$ protein of fibroblast cells. 

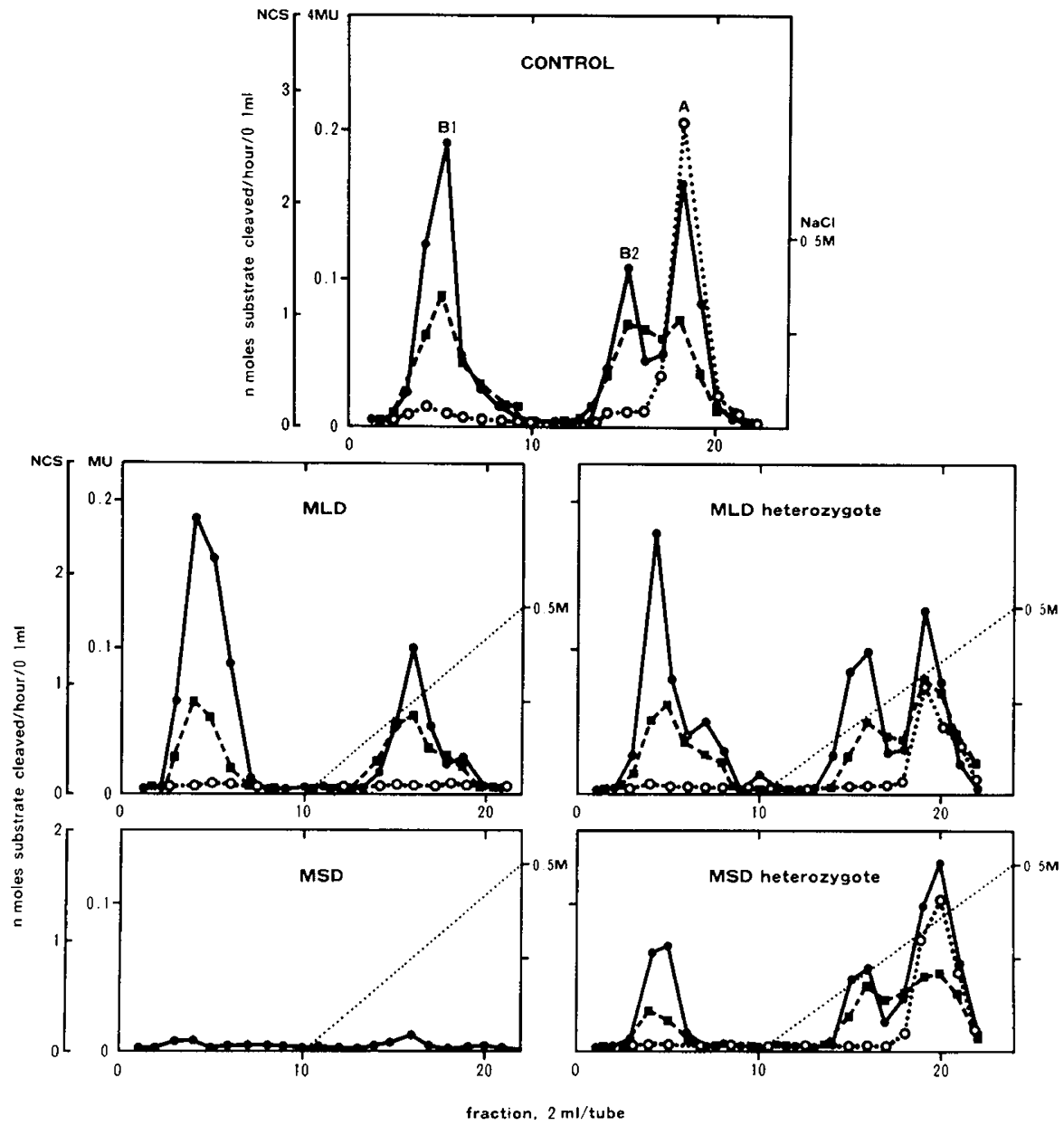

Fig. 4. DEAE-Sepharose column chromatographic patterns of 4-methylumbelliferyl (4-MU) and $p$-nitrocatechol ( $p$-NC) sulfate sulfatase in leukocyte from controls, metachromatic leukodystrophy (MLD), MLD heterozygote, multiple sulfase deficiency (MSD) and MSD heterozygote. The activities were normalized on the basis of $5 \mathrm{mg}$ protein. (-), 4-MU sulfatase (using $10 \mathrm{mM}$ sulfate in $0.2 \mathrm{M}$ acetate buffer, $\mathrm{pH} 5.3$ ); $(\mathrm{O}-\mathrm{O}$ ), p-NC sulfate (reagent A by Baum's method; and ( $\square$ ), p-NC sulfatase (reagent B by Baum's method).

and $54 \%$ in heterozygotes for $\mathrm{MSD}$, respectively. Heparin Nsulfatase was $0.5 \%$ in MSD patients.

Various sulfatase activities in leukocytes (Fig. 2). Arylsulfatase A activity in leukocytes from MSD patients and obligate heterozygotes were $5 \%$ and $60 \%$ less than that of controls, respectively. Arylsulfatases B1 and B2 activities were practically absent in MSD patients and $70 \%$ in its heterozygotes. Arylsulfatase C activity was deficient in MSD patients and 59\% in heterozygotes. A sister of the Japanese case of MSD showed arylsulfatases A, B1, and $\mathrm{B} 2$, and $\mathrm{C}$ activities within normal ranges.

$D E A E$-sepharose column chromatography of 4-MU arylsulfatases from leukocytes and cultured skin fibroblasts. Figures 3 and 4 show the column chromatographic patterns of 4-MU and $p$ nitrocatechol arylsulfatases from cultured skin fibroblasts and leukocytes of patients with MLD, MSD, and their heterozygotes. In control fibroblasts, 4-MU arylsulfatase activities were fractionated into three major fractions, designated as A, B1, and B2. The fraction $\mathrm{B} 2$ is considered to be a minor arylsulfatase B reported by Fluharty et al. (11).

The MSD patient showed a deficiency of each component of the 4-MU arylsulfatases as well as of $p$-nitrocatechol arylsulfatase. In the heterozygote, each component of arylsulfatase activity was reduced to roughly one-half the control, as shown in Figure 3. The MSD patient and heterozygote did not show different elution patterns of arylsulfatases, as compared with those of controls. Using $p$-nitrocatechol sulfate as a substrate, these patterns were essentially similar to those of control. Arylsulfatases A, B1, and B2 activities in the MSD patient's leukocytes were practically absent.

Enzyme characteristics of 4-MU arylsulfatases A, B1, and B2.
$\mathrm{Km}$ values of arylsulfatases A, B1, and B2 in control leukocytes were $0.2,0.1$, and $0.5 \times 10^{4} \mathrm{M}$, respectively. In the MSD heterozygote these are $0.2,0.3$, and $0.3 \times 10^{4} \mathrm{M}$, respectively. Optimal pHs of arylsulfatases A, B1, and B2 in control leukocytes were 5.6, 5.2 and 5.2, respectively. The MSD heterozygote showed a similar optimal $\mathrm{pH}$ to those of control. Effects of ions by $\mathrm{Ba}^{++}$, $\mathrm{Mg}^{++}, \mathrm{Ca}^{++}, \mathrm{Ag}^{++}$, and $\mathrm{Hg}^{++}$in MSD heterozygote were essentially similar to those of control (the data is not shown). Results obtained from cultured skin fibroblasts were similar to those obtained from leukocytes for both the MSD patient and its heterozygotes.

\section{DISCUSSION}

Several sulfatase activities including arylsulfatases A, B1, B2, $\mathrm{C}$, cholesterol sulfatase and heparin $\mathrm{N}$-sulfatase were deficient or reduced in activity in cultured skin fibroblasts and leukocytes from patients with MSD. Deficient activities of several sulfatases in cultured skin fibroblasts with MSD have been described previously $(3,7)$, whereas these enzyme activities in leukocytes from MSD patients have been described. Several sulfatase activities in MSD leukocytes were practically absent, as compared with those from MSD cultured skin fibroblasts in which significant amounts of residual activities were present. This difference might be due to culture conditions, because Fluharty et al. $(12,13)$ reported that alkaline $\mathrm{pH}$ in the culture medium induced arylsulfatase $\mathrm{A}$ in MSD fibroblasts and also fetal calf serum contained predominantly arylsulfatase B rather than arylsulfatase A (unpublished observation).

Several sulfatase activities in heterozygotes with MSD have not 
been reported previously. As shown in Figures 1 and 2, several sulfatase activities in cultured skin fibroblasts were almost onehalf of controls in three heterozygotes of MSD patients, whereas these enzyme activities in leukocytes from MSD heterozygotes overlapped with control individuals. These differences might be due to heterogeneous populations in leukocytes as compared with those of cultured skin fibroblasts. It is therefore advisable to detect heterozygotes in cultured skin fibroblasts.

The reduced activities of arylsulfatases $\mathrm{A}, \mathrm{B} 1, \mathrm{~B} 2$, and $\mathrm{C}$ in leukocytes and cultured skin fibroblasts were confirmed by the experiments with DEAE-Sepharose column chromatography. The presence of an abnormal peak with 4-MU sulfatases was not observed in either leukocytes or cultured skin fibroblasts preparations. Enzyme kinetics and characteristics of isolated 4-MU sulfatases in leukocytes and cultured skin fibroblasts from the heterozygote and the patient with MSD suggest that the reduced activities of the various sulfatases are due to quantitatively reduced normal enzymes, indistinguishable from the enzymes in normal controls. These findings also confirmed the results of Fiddler et al. (10) who showed that arylsulfatases A and B in this disorder are reduced in their levels of cross reacting materials against antiarylsulfatases $\mathrm{A}$ and $\mathrm{B}$ antibodies.

Reduced activities of various sulfatases in MSD heterozygotes may support the hypothesis that the multiple sulfatase deficiencies in this disorder are probably due to a single mutation of a sulfatase gene controlling system. The previous hypotheses such as a mutation in a subunit, cofactor, or inhibitor common to these sulfatases can be ruled out by immunologic studies reported by Fiddler et al. (10). Of interest is that affected enzymes in this disorder are produced by both autosomal and X-linked chromosomes. Arylsulfatases $\mathrm{A}$ and $\mathrm{B}$ and heparin $\mathrm{N}$-sulfatase are known to be localized in autosomal genes (arylsulfatase $\mathrm{A}$ in chromosome number 22 (6) and B in chromosome number 5) (6), whereas arylsulfatase $C$, cholesterol sulfatase, other steroid sulfatase and sulfoiduronate sulfatase are considered to be localized in X-chromosomes (steroid sulfatase in Xg locus) (17). Most recently, cell fusion studies in which MSD cells were fused with other sulfatase deficient disorder such as MLD, Maroteaux-Lamy syndrome, Sanfilippo A, steroid sulfatase deficient disorder and Hunter syndrome support the hypothesis than an enzyme deficiency in MSD is different from that causing specific sulfatase deficiencies $(5,14)$. Intermediate activities of various sulfatases in MSD heterozygotes suggest that a defect of post-translational process, like I-cell disease, is not likely because the heterozygotes of I-cell disease did not show the intermediate activities of various lysosomal enzymes (15). The occurrence of these different enzyme deficiencies in MSD patients suggests that there might be a defect in a gene controlling various sulfatase activities.

\section{REFERENCES AND NOTES}

1. Austin, J., Armstrong, D., and Shearer, L.: Metachromatic form of diffuse cerebral sclerosis (metachromatic leukodystrophy; MLD) V. The nature and significance of low sulfatase activity; A control of low sulfatase activity. Arch. Neurol., 13: 593 (1965).

2. Austin, J. A.: Studies in metachromatic leukodystrophy XII. Multiple sulfatase deficiency. Arch. Neurol., 28: 258 (1973).

3. Basner, R., von Figura, K., Grössl, J., Kresse, H., and Mlekusch, W.: Multiple deficiency of mucopolysaccharide sulfatases in Mucosulfatidosis. Pediatr. Res., 13: 1316 (1979).

4. Baum, H., Dodgson, K. S., and Spencer, B.: The assay of arylsulfatases A and B in human urine. Clin. Chim. Acta, 4: 453 (1959).

5. Chang, P. L. and Davidson, R. G.: Complementation of arylsulfatase $A$ in somatic hybrids of metachromatic leukodystrophy and multiple sulfatase deficiency disorder fibroblasts. Proc. Natl. Acad. Aci. USA, 77: 6166 (1980).

6. DeLuca, D., Brown, J. A., and Shows. T. B.: Lysosomal arylsulfatase deficiencies in humans; Chromosomal assignments for arylsulfatase A and B. Proc. Nat1. Acad. Sci. USA, 76: 1957 (1979).

7. Eto, Y., Weismann, U. N., Carson, J. H., and Herschkowitz, N. N.: Multiple sulfatase deficiency in cultured skin fibroblasts; occurence in patients with a variant form of metachromatic leukodystrophy. Arch. Neurol., 30: 153 (1974).

8. Eto, Y., Rampini, S., Weismann, U., and Herschkowitz, N. N.: Enzymic studies of sulphatases in tissues of the normal human and in metachromatic leukodystrophy with multiple sulfatase deficiencies; arylsulfatases A, B and C, cerebroside sulfatase, psychosine sulfatase and steroid sulfatases. J. Neurochem., 23: 1161 (1974).

9. Eto, Y., Numaguchi, S., and Handa, T.: Urinary acid mucopolysaccharides in multiple sulfatase deficiency (mucosulfalfatidosis) Eur. J. Pediatr., 132: 207 (1979).

10. Fiddler, M. B., Vine, D., Shapira, E., and Nadler, H. C.: Is multiple sulfatase deficiency due to defective regulation of sulfohydrolase expression? Nature, 282: 98 (1979).

11. Fluharty, A. L., Stevens, R., Sanders, D. L., and Kihara, H.: Arylsulfatase B deficiency in Maroteaux-Lamy syndrome cultured fibroblasts. Biochem. Biophys. Res. Commun., 59: 455 (1974).

12. Fluharty, A. L., Stevens, R., Sanders, D. L., and Kihara, H.: Presence of arylsulfatase A (ARS A) in multiple sulfatase deficiency disorder fibroblasts. Amer. J. Hum. Genet., 30: 249 (1978).

13. Fluharty, A. L., Stevens R. L., Davis, L. C., Shapiro, L. J., and Kihara, H.: Arylsulfatase A modulation with $\mathrm{pH}$ in multiple sulfatase deficiency disorder fibroblasts. Amer. J. Hum. Genet., 31: 574 (1979).

14. Horwitz, A. L.: Genetic complementation studies of multiple sulfatase deficiency. Proc. Natl. Acad. Sci. USA, 76: 6496 (1979).

15. Leroy, J. G. and Van Elsen, A. F.: I-cell disease (Mucolipidosis II): Serum hydrolases in obligate heterozygotes. Human Genetik, 20: 119 (1973).

16. Lowry, O. H., Rosebrough, N. J., Farr, A. L., and Randall, R. J.: Protein measurement with the Folin phenol reagent. J. Biol. Chem., 193: 265 (1951).

17. Mohandes, T., Shapiro, L. J., Sparkes, R. S. and Sparkes, M. C.: Regiona assignment of the steroid sulphatase X-linked ichthyosis locus. Identification for a non-inactivated region on the short arm of the human X-chromosome. Proc. Natl. Acad. Sci. USA, 76: 5779 (1979).

18. Murphy, J. V., Wolfe, J. V., Wolfe, H. J., Balasz, E., and Moser, H. W.: A patient with deficiency of arylsulfatase A, B, C and steroid sulphatases, associated with storage of sulfatide, cholesterol sulfate and glycosaminoglycans. in "Lipid Storage Disorder: Enzymatic defects and clinical implication", edited by Bernsohn, J. and Grossman, H. J., p. 67, Academic Press, New York, (1971).

19. Schmidt, R., von Figura, K., Paschke, E., and Kresse, K.: Sanfilippo's disease type A: sulfamidase activity in peripheral leukocyte of normal, heterozygous and hemizygous individuals. Clin. Chim. Acta, 80: 7 (1977).

20. Snyder, R. A. and Brady, R. O.: The use of white cells as a source of diagnostic materials for lipid storage diseases. Clin. Chim. Acta, 25: 331(1969).

21. The authors wish to express thanks to Dr. L. Margolis (Department of Hygiene, University of North Carolina, USA) for kindly correcting our manuscript.

22. Reprint requests to Dr. Y. Eto, Department of Pediatrics, The Tokyo Jikei University School of Medicine, Nishishinbashi 3-25-8, Minato-ku, Tokyo, Japan).

23. Received for publication September 23, 1980.

24. Accepted for publication June I, 1982. 